\title{
La herencia centralista de la izquierda chilena y la irrupción de un progresismo regionalista autonomista ${ }^{*}$
}

\author{
The centralist heritage of the chilean left and the irruption of a regionalist \\ autonomist progressive faction
}

\author{
Esteban Valenzuela $^{1}$ y Edison Ortiz $^{2}$
}

\begin{abstract}
Resumen: El artículo rescata la reactivación de la tradición regionalista autonomista de una parte de la izquierda chilena que ha pujado por un proceso de descentralización en el más centralista Estado de Sudamérica y de la OCDE. Se concluye que dicha irrupción logró permear el informe final de la Comisión para la Descentralización en el año 2014, pero cuyas principales iniciativas fueron bloqueadas por el Partido del Orden, conformado por grupos dominantes en la derecha y de la antigua Concertación en alianza con los empresarios. No obstante, tuvieron el mérito de haber puesto la demanda en la agenda, develado la naturaleza portaliana ${ }^{3}$ de la izquierda metropolitana, empujado la elección de gobernador regional y logrado que movimientos regionalistas verdes se sumen a los movimientos sociopolíticos estudiantiles en favor de un bloque político amplio transformador que incluya la perspectiva de descentralización sustantiva y popular como uno de los ejes de una propuesta socialista para Chile. Tal vertiente estuvo presente en el origen de la izquierda chilena que luego fue subsumida por las visiones socialdemócratas bonapartistas que solo buscan fortalecer el Estado central. En el actual gobierno ambas izquierdas debatieron y se diferenciaron en la Comisión Asesora Presidencial para la Descentralización.
\end{abstract}

Palabras Clave: Izquierda, centralismo, autonomismo, descentralización, Comisión Asesora Presidencial, Chile.

Abstract: The article rescues the reactivation of the regionalist autonomist tradition of
a part of the Chilean left that has pushed for a process of decentralization in the most
centralist State of South America and of the OECD. It is concluded that this irruption
managed to permeate the final report of the Commission for Decentralization in 2014,
but whose main initiatives were blocked by the Party of Order, made up of dominant
groups on the right and the old Concertación in alliance with economic groups.

\footnotetext{
${ }^{*}$ Fruto de investigación del FONDECYT 1150684 Protesta Regional y Ciclo de Reformas en Chile.

${ }^{1}$ Esteban Valenzuela Van Treek, chileno, Universidad Alberto Hurtado, Dr. en Historia de la Universidad de Valencia, Máster en C. Política (PUC) y en Desarrollo (UW-Madison) evalenzuelavt@gmail.com

${ }^{2}$ Edison Ortiz González, chileno, profesor de las Universidades Alberto Hurtado y Santiago de Chile. Dr. en Historia de la U. de Valencia y Magíster en Historia de la USACH. edison@ortiz.as

${ }^{3}$ Diego Portales fue el instigador de la coalición conservadora que venció en 1830 destruyendo el proceso constituyente liberal en Chile (1823-29). Como ministro de Estado impulsó la presidencialista, autoritaria y centralista Constitución de 1833.
} 
However, they had the merit of having put the demand on the agenda, unveiled the portalian nature of the metropolitan left, pushed the election of regional governor and achieved that regional regionalist movements join the socio-political student movements in Favoring a broad political block of transformation that includes the perspective of substantive and popular decentralization as one of the axes of a socialist proposal for Chile. Such a shed was present in the origin of the Chilean left that was later subsumed by the Bonapartist social-democratic visions that only seek to strengthen the central state. In the current government, both leftists debated and differed in the Presidential Advisory Commission for Decentralization.

Key Words: Left, centralism, autonomism, decentralization, Presidential Advisory Commission, Chile.

Recibido: 18 diciembre 2016

Aceptado: 22 febrero 2017

\section{Introducción: La pugna entre izquierdas centralistas y descentralizadoras en el Chile portaliano}

El artículo busca explicar el fracaso relativo de la corriente de izquierda descentralizadora en Chile, federal o autonomista, la que sí ha crecido en otros países de América Latina en la última década en base a un ideario común que sintetizamos en los siguientes aspectos: crecimiento de la descentralización sin desmantelar el Estado central, mayor participación popular, mejora sustancial de los servicios sociales, proactividad pública en la gestión del territorio incluyendo el desarrollo económico local, reapropiación de los recursos naturales y mayor carga tributaria a los poderosos, valor de la colegiatura y la democracia radical con rendición de cuentas públicas (Carrión y Ponce 2015, Valenzuela 2015).

Chile al igual que el orbe ha vivido la disputa de enfoques entre la izquierda jacobina centralista y las izquierdas comunalistas, federalistas o autonomistas. Si vamos al origen de la palabra izquierda en la revolución francesa, se observa que quienes querían profundizar la misma se dividían en jacobinos radicales que desde el Estado central buscaban imponer su modelo de sociedad con todos los medios (Martin 1945, Vovelle 1999), versus los territorialistas que propugnaban modelos comunales y/o federales, sujetos plurales que en los estados generales de los pueblos oprimidos buscaban soluciones diversas para la emancipación, combinando libertad con igualdad y fraternidad. Tras el fracaso parcial de la revolución y su síntesis en el régimen napoleónico (se acabó el antiguo régimen, el estado central modernizó e invirtió en las capas populares y campesinas, aunque en forma autoritaria), Francia se convirtió en el paradigma de país centralista en Europa con la herencia semi autoritaria del bonapartismo iluminista en concordancia con la visión jacobina (Bobbio y Matteuci 1988, Bobbio 2005 y 2009). No obstante, la propia 
experiencia socialista anarquista de la revuelta de la Comuna de París en 1971, mostró un breve episodio de toma de poder desde una mirada de autogestión territorial (Ceamanos 2014).

En contraste a la construcción desde la estatalidad central, desde inicios del siglo XIX en paralelo a la independencia americana, las corrientes socialistas idealistas comunitaristas de Saint-Simon, Fourier y Owen promueven modelos utópicos autogestionarios y autonomistas de emancipación proletaria y fraternidad con experiencias en Francia y en sindicalismo inglés (Desanti 1973), influyendo las diversas rebeliones sociales y liberales contra las repúblicas militaristas oligárquicas que se impusieron con un orden desigual (Abramson 1999). Dichas corrientes liberales progresistas y federalistas encabezaron la izquierda del siglo XIX, los pipiolos en el caso chileno que pugnaron por un estado federal con poder en las ocho provincias fundantes de la República y mayor inversión estatal en educación (Salazar 2005 y 2011; Valenzuela 1999), además de influir en el pensamiento federalista de Infante (Valenzuela 2008) y en la generación rebelde que creó los clubes de la igualdad y la reforma en los 1840s. Tras la triple derrota de las coaliciones transformadoras del siglo XIX conformada por pipiolos, federalistas y mapuches en las guerras civiles de 1829, 1851 y 1859 (Valenzuela 1999), se impone la república oligárquica que integra a su bloque a los liberales rojos que fundaron el Partido Radical (Matta y Gallo), marcando el fracaso del autonomismo provincial en dicho siglo, la entronización del modelo centralista y su consecuencia más significativa: la cooptación del disidente y (Ortiz y Valenzuela 2014).

Durante la centuria precedente, fue Luis Emilio Recabarren, concejal del partido Demócrata, obrero linotipista, líder de los trabajadores en el norte, fundador del Partido Obrero Socialista (POS, luego Partido Comunista), quien en la lucha territorial construyó Estado desde abajo haciendo rebrotar la izquierda comunalista o mancomunal. Así lo manifestó con pasión en su visita a Buenos Aires en el año de la revolución bolchevique en 1917: "El camino está claro: Sólo la clase trabajadora or-ganizada en el Partido Socialista podrá afrontar la responsabilidad de hacer una buena administración municipal. Sólo los proletarios saben lo que es vivir en conventillos, inquilinatos o barrios inmundos, per-petuamente encharcados y hediondos; sólo ellos sa-ben lo que es alimentarse al capricho de almacene-ros y vendedores sin pudor; por eso, y por todas las razones que se explican más adelante, el pueblo de la capital argentina y de todas las comunas, debe decidir, sin vacilar, de su futura suerte". ${ }^{4}$

Esta visión comunalista de la izquierda se desdibujó luego por los partidos que se tradicionalizaron y menospreciaron la lucha desde los territorios, que se erigieron a partir del modelo soviético - el asalto al palacio de invierno para controlar el Estado - y se reafirmaron con rápido éxito electoral del Frente Popular y el predominio de la izquierda

\footnotetext{
${ }^{4}$ Luis Emilio Recabaren, discurso en Buenos Aires en septiembre de 1917. Lo que puede hacer la municipalidad en manos del pueblo inteligente. Fuente: El Pensamiento de Luis Emilio Recabarren, Tomo II, págs. 425-463. Editorial Austral. Santiago de Chile, diciembre 1971.
} 
socialdemocrática centralista que buscaba reformas defensivas sin modificar el fondo del régimen portaliano (Salazar 2011). Es decir, se desdibuja la izquierda popular de raigambre federalista en el siglo xix y de impronta comunalista en los albores del xx, hasta que reemerge hoy con el movimiento mapuche, grupos verdes y federalistas, movimientos de pobladores por mejor vivienda y derechos a la ciudad, facciones de la izquierda tradicional (el alcalde comunista Jadue en Recoleta que construye farmacias populares el $2015^{5}$ ) y los nuevos movimientos de la izquierda universitaria que enfatizan el autonomismo territorial como uno de sus apuestas estratégicas junto a la educación pública, la recuperación estatal de los recursos naturales y empoderamiento ciudadano.

En Iberoamérica la izquierda federal o autonomista tiene orígenes diversos, desde el influjo en los 1980s de vascos y catalanes en favor de poder territoriales fuertes y con liderazgo urbano y socioeconómico en la época de servicios (Castells 1997, Borja 2014), la apertura mexicana a través de la gestión del DF por Cuauhtémoc Cárdenas y la gestión emblemática que sectores progresistas e izquierdistas realizan en ciudades como Bogotá, Medellín, Quito, Rosario, La Paz-El Alto, Montevideo y Porto Alegre, lo que conformaría lo que Carrión y Ponce (2015) el giro a la izquierda de los gobiernos locales de América Latina. En paralelo, el movimiento indígena irrumpe con un discurso que reivindica el poder territorial, la autonomía, la distribución del poder y las formas alternativas de Estado, desde la irrupción de los zapatistas en Chiapas, la movilización andina con Felipe Quispe en Bolivia y el Partido Pachacuti en Ecuador, además de la activación del movimiento autonomista mapuche en Chile desde 1996 (Preciado y Uc 2010).

\section{La presicracia del postpinochetismo: la mera administración del modelo}

Chile naturalizó el gobierno central como eje del desarrollo en un régimen político presicrático donde se combina presidencialismo con centralismo (Valenzuela 2007), a diferencia de otros modelos presidenciales latinoamericanos que sí tienen fuerte poder regional como Brasil, Colombia, Argentina, y crecientemente Perú, Bolivia y Ecuador (Rosales 2012). Si bien a comienzos de la transición hubo un esfuerzo por democratizar los municipios y dotar de legalidad y atribuciones a los gobiernos regionales (Martner, 1993) lo cierto es éste no pasó mucho más allá de elegir y transferir una que otra competencia y la realidad evidenció que la concertación, pese a sus promesas no avanzó mucho por esos derroteros (Valenzuela y Ortiz, 2013) y en la medida que avanzó el tiempo y los gobiernos democráticos se consolidó más bien el modelo bróker que hace de los parlamentarios de la coalición oficialista los verdaderos señores de feudales que tranzan sus votos con La Moneda a cambio de los beneficios y cooptación del Estado en las provincias (El Mostrador, 10 de marzo de 2015).

\footnotetext{
${ }^{5}$ En la hegemonía del Estado empresario, el alcalde Daniel Jadué logró vencer la resistencia de la Contraloría General de la República y el Ministerio de Salud por el lobby de las farmacéuticas, para imponer en un centenar de municipios la creación de Farmacias Populares con precios baratos de fármacos para enfermedades crónicas.
} 
La Concertación que ha dominado la gestión del Estado central desde 1990 desvalorizó la trasformación territorial democrática popular con poder en la renta, primando la verticalidad centralista y la cooptación, entendida repartición menor de renta sin empoderar, integrando a parte de los críticos a la elite dominante- versus la autonomía que implica la elección democrática de representantes, poder político, devolución de recursos económicos significativos por ley — sin discrecionalidad central - y potestades reales de autogobierno con competencias relevantes.

Chile, como país con una matriz profundamente centralista tiende, como lo han demostrado diversas investigaciones, al estancamiento estructural, económico y también en términos de desarrollo territorial; este retraso tiene otra de sus facetas en el decaimiento estadístico, en la superación de indicadores básicos, tales como la calidad en la educación — tema por el que el gobierno de turno y sus antecesores han tenido que lidiar irrenunciablemente desde 2006 con la Revolución Pingüina ${ }^{6}$ - , la superación de la pobreza — con la escasez de políticas sociales que se hagan cargo de este problema a nivel rural y regional, centrándose la mayoría de los esfuerzos en la erradicación de campamentos en la Región Metropolitana y en el mero otorgamiento de subsidios con fines clientelares-, seguridad ciudadana — con un nivel de victimización creciente en Santiago y con muy poca información de las regiones - , descontaminación de las ciudades — con la puesta en marcha del Transantiago en 2007, se erradican de Santiago los microbuses más contaminantes y son trasladados en su mayoría a continuar con sus labores en regiones, trasladando el problema del smog y sus consecuencias para la salud a una zona menos "preponderante" del país.

Este escenario de hipercentralismo, no solo es posible de constatar a nivel social; políticoelectoral, el cual garantiza la formación de dos coaliciones casi empatadas que no dan cabida a la emergencia de nuevos actores, además de un presidencialismo sumamente arraigado en el imaginario socioidentitario de la política chilena, aferrada a un poder central omnipotente que en regiones tiene a la figura del intendente designado como su principal referente.

A su vez, el desconocimiento de las ideas federalistas y/o regionalistas sus beneficios al país, han sido frecuentes en la historia política chilena, basta solo con recordar las propuestas de José Miguel Infante y su federalismo al estilo estadounidense, que no tuvo un buen recibimiento, al punto de asociar este tipo de iniciativas y a los intelectuales de la época con el anarquismo. Desde dicha época emergen opiniones políticas que con el tiempo se hacen creencias populares (que han inventado las elites) acerca de lo pernicioso institucionalmente que podría llegar a ser un modelo descentralizado: se habla anarquía, de poco poder estatal, de pérdida de recursos, de fragmentación territorial, secesión, entre otros; mientras que los argumentos se basan en simplismos que aluden a que un país pequeño como Chile no requiere de reformas de este tipo, o que simplemente, la política ni las personas se encuentran preparadas para un cambio de esta índole. Y claro, toda la argumentación viene dada desde la oligarquía metropolitana que era precisamente la que se

\footnotetext{
${ }^{6}$ Movimiento de estudiantes universitarios y secundarios en el año 2006 que masivamente pujaron por educación pública.
} 
compraba escaños en el parlamento en regiones y que luego argumentaban en favor de sí mismos. Ya lo dijo alguien: el poder produce verdad y la verdad se cosifica en las instituciones (Foucault, 1970).

Las razones que se pueden esbozar para defender una lógica federal-regionalista se pueden dividir en tres grandes temáticas:

a.- Superación del estancamiento económico estructural: la falta de proyectos en regiones y la falta de apoyo que se genera desde Santiago, no permiten un buen desarrollo en términos de capitales semilla para iniciativas en lugares más apartados, ni un soporte relevante para el emprendimiento. La transferencia económica a regiones tiende a ser de tipo subsidiario, en el que se garantiza únicamente una ayuda parcializada que pretende solo mejorar la situación ya existente, pero en ningún fomentar nuevos proyectos para el mejoramiento de las condiciones de vida mediante la innovación.

b.- Dinamización de políticas y programas: el poder central tiene múltiples expresiones en la política que se imparte mediante programas que llegan a todo el país. Un claro ejemplo de este tipo de práctica es el SIMCE, el cual pretende estandarizar la realidad de todos los estudiantes del país, sin importar las diferencias intrínsecas en la enseñanza que pueden concretarse en las distintas latitudes del país, ni en sus diversos grupos socioeconómicos. Asimismo, la creación de programas de gobierno que no son aplicables a todas las regiones como tampoco a las culturas que habitan el país y entre las que cabe mencionar decisiones que han tenido lugar últimamente en cuanto a la subvención del transporte público durante todo el año para el estudiantado; pero con pleno desconocimiento de los estudiantes de regiones, quienes también tienen las mismas necesidades y actividades que aquellos que se desarrollan en el ámbito santiaguino.

c.- Superación de la crispación política: el modelo actual meramente garantiza la persistencia de los mismos gobernantes y sus gabinetes por un tiempo extenso, con una oposición condenada a la crítica de gobierno de turno con muy pocos espacios para el debate y el diálogo político y que obliga a los actores políticos a deambular entre la disidencia marginal (Infante) o la cooptación (Matta) tal cual como se ha descrito (Ortiz y Valenzuela, 2014).

\section{Un poco de historia: Centralismo y Cooptación en nuestra oligárquica experiencia democrática}

La pólvora que alimenta desde el siglo XIX la agresión centralista a los territorios en Chile, se funda tanto en el presidencialismo autoritario diseñado por Portales, como en el liberalismo del orden que introdujo la visión homogénea de país, permeando a las elites de fetichismo y mentalidad controladora y que tuvo como escenario de fondo el disciplinamiento social. Así, se aplacó a fuego a los federalistas-regionalistas en 1830, 1848, 1851 y 1859, y luego se colonizó con violencia La Araucanía (1865-1880), despojando a los mapuches de su territorio y de sus derechos políticos. La república oligárquica parlamentaria (1891-1925), al igual que el período desarrollista dominado por 
corrientes centro-izquierdistas (1938-1973), fortalecieron la concentración del poder económico en Santiago, con municipios mínimos, la negación a la consolidación de provincias autónomas y la nacionalización homogénea que folklorizó la representación de lo indígena, negándole derechos étnicos y territoriales (Marimán, 2012) y que instaló con la constitución de 1925 la asamblea provincial como gran mecanismo de participación pero que dependía del intendente quien nunca la convocó y que tampoco, las voces regionales reclamaron. Con posterioridad este modelo fue acentuado por la regionalización autocrática y meramente económica de la dictadura, con sus intendentes militares, y administrada por la Concertación sin reformas, convirtiendo a Chile en el único país de la OECD sin democracia regional ni autonomías territoriales, sin devolución significativa de impuestos y recursos a las mismos —entes subnacionales administran el 14\% de los recursos fiscales versus el 50\% de los países desarrollados—-, sin elección de autoridades macro territoriales. Nada de autonomía territorial a las etnias - aymaras, rapanui, atacameños - ni pacto político relevante con los mapuches, el pueblo-nación al cual los españoles le reconocieron su territorio al sur del río Biobío (Valenzuela, 1999).

La maquinaria dominadora del gobierno central ha combinado la represión directa contra los territorios rebeldes, con las prácticas cooptadoras: recursos mínimos, comisiones de estudios, prebendas a dirigentes que se cooptan, absorción de los movimientos regionalistas a partidos nacionales, leyes especiales a territorios críticos (zonas extremas), dádivas y micropolítica integrativas a mapuches y otras etnias.

Sin embargo, a los aislados fenómenos de la Atacama libre de 1859 y el imperio del Partido Regionalista en Magallanes entre 1932-1945, la domesticación de los territorios siempre resulta al final un fracaso que concluye con la irrupción de movilizaciones y recuperación del proyecto histórico autonómico de los mapuches. Con sus raíces en la lucha contra la dictadura - Ad Mapu y otras organizaciones-, hacia 1990 se levantan propuestas de región autónoma mapuche, y desde 1995 comienza la toma de bosques y fundos mal habidos por parte de comunidades, lo que desata la creación del Consejo de Toda las Tierras, la Coordinadora Arauco-Malleco, Identidad Lafkenche, entre otras organizaciones que apoyan el rescate étnico, lingüístico, territorial y político. A la palabra autonomíaautodeterminación de los mapuches, hacia el año 2000 segmentos de la elite rescatan la demanda de intendentes elegidos - los Federales_- y comienza un ciclo de movilizaciones territoriales para obtener soluciones económicas ante la alta cesantía (Arica, Illapel, LotaCoronel, Huasco), oposición a mega proyectos eléctricos y mineros que afectan la ecología de las comunidades — desde los pehuenches del Alto Biobío a Pascua Lama-, hasta la irrupción en el bienio 2011-12 de un regionalismo politizado que demanda subsidios, fondos estructurales y poderes (Magallanes, Aysén, Calama).

En Chile, es escasa tanto la historiografía que explica la irracionalidad de su centralismo así como el análisis político de las razones de la cooptación de los movimientos regionalistas, de la fragilidad de estos grupos para crear una coalición interregional (nacional) y de las razones de fondo de la elite del poder para rechazar esta dimensión de la democratización y desarrollo del país; por tanto, esta investigación busca indagar de manera novedosa en dicho déficit, combinando el método histórico con una propuesta de análisis político 
comparado para analizar el "modelo de cooptación", sus fases y su resultado en una coalición regionalista débil. Se aborda, además, el fenómeno centralista como rareza, tomando distancia de la herencia político cultural que sobre el mismo han construido las elites políticas metropolitanas que se distribuyen de derecha a izquierda.

El grueso de los investigadores toma aspectos parciales, apuntan a la construcción de las regiones desde lo social y cultural después de su creación tecnocrático-autoritaria en 1974, lo que venía gestándose desde el desarrollismo cepaliano desde 1969 (Boisier, 1989). Entonces, se confunden los estudios con medidas puntuales de desconcentración, sin analizar el elemento histórico-político sobre la naturaleza del Estado que se constituyó a partir de 1830 con dominación de los territorios y traba a su democratización. El sistema político chileno, marcado por su centralismo presidencial, muestra una gran capacidad de permanencia desde el triunfo conservador-portaliano (1830) sobre federalistas y pipiolos liberales, superando guerras civiles y protestas regionalistas por la vía del uso de la violencia estatal y de mecanismos de cooptación de dichos disidentes al poder central.

Teóricamente, se ha masificado el término cooptación, que ha ganado terreno en las ciencias políticas e históricas como un concepto más amplio que el mero clientelismo, ya que supone que el Estado secuestra las demandas ciudadanas con dádivas (Haldenwang, 1999), buscando mantener la alianza de grupos estratégicos con la elite dominante (Gerschewski, 2010). El clientelismo es un vínculo asimétrico con grupos para aprovechamiento electoral; la cooptación, en cambio, es para evitar transformaciones políticas en una lógica democrática de dispersión del poder, ya que busca evitar rebeliones por la vía de lograr una cooperación cínica basada en concesiones para distribuir parte de la renta (Gandhi, 2006: 2). En el caso chileno, se contrastará la domesticación de las rebeliones regionales y sus movimientos por esta vía, centrada en otorgar algunas rentas e integrar al sistema.

El "modelo de cooptación" se repite históricamente, aplaca la demanda regionalista y mantiene un caso excepcional de delegación central en los territorios (Salazar y Valenzuela E., 1999). Chile, como lo señalamos anteriormente, es el único país de la OECD sin elegir gobiernos regionales y el único de tamaño medio-grande sin hacerlo en América: Estados Unidos, Canadá, Brasil, México, Colombia, Argentina y recientemente Perú eligen gobiernos regionales, y tienen más de un $30 \%$ de gasto público descentralizado. Chile permanece bajo el promedio de América Latina en gasto subnacional, con solo un 14\% (López, 1995: Nickson, 1995; Rosales, 2012), no obstante la dimensión territorial que también abarca sus problemas de equidad (Messner, 1996). La resistencia a este elemento democrático moderno amerita ahondar en sus lógicas, complejidad y materialización histórica, que son el objeto de la investigación.

El modelo se reproduce históricamente en la tradición presidencialista del continente que proyecta elementos monárquicos y populistas, así como la construcción estatal desde arriba (Veliz, 1984; Góngora, 1980) y con violencia endémica (Jara, 1979); sin embargo, desde arreglos federales del siglo XIX como en Argentina, Colombia y Brasil, a nuevas olas democratizadoras-descentralizadoras, América Latina se ha movido hacia la 
descentralización, con la excepcionalidad chilena, donde el autoritarismo se reforzó en la Constitución de 1980, con un presidencialismo exacerbado (Cea, Godoy y Cumplido, 1992). Casi todos los liberales y federalistas que protagonizaron las rebeldías contra el régimen portaliano en 1848 y 1851 tuvieron inspiración en el pensamiento francés y en las ideas del destacado federalista José Miguel Infante. Muchos de los liberales después adhirieron al liberalismo del orden y al nacionalismo homogeneizador que despreció la autonomía provincial y arrasó con los mapuches. Lastarria y Vicuña Mackenna tienen expresiones contradictorias. Sin duda, el más coherente fue Francisco Bilbao, quien se apartó de la visión menospreciadora de los provincianos e indígenas que se aprecia en las elites continentales, teniendo en Sarmiento un epítome con su libro Civilización o barbarie. En cambio, Bilbao en Evangelio americano, fustiga la visión colonizadora del pensamiento occidental y valora la otredad. El poder - Santiago - tiene su prueba histórica con reconocer al otro, las regiones y el poder mapuche. José Rodríguez lo rescata: la otredad de Chile, según Bilbao, es el mapuche; así, cuando anuncia que el texto fundacional de Chile, La Araucana, debe leerse en todas las escuelas, está proclamando el lugar central que el indio debiese ocupar en la nación. Lautaro salvó al indómito Arauco, y Arauco aún puede levantarse por entre las razas esclavizadas de América y decir: "España yo te vencí; América, yo te vengué'. Esperemos que aún dirá: Fraternidad, seré tu brazo... y eres tú Chile, patria mía, quien debe llevar la palabra de la caridad, de la ciencia y de la redención a la tierra de Arauco" (Bilbao, 1988: 299).

Tras la estabilidad de los decenios conservadores (1830-1860), afectada por la guerra civil contra los alzados de Atacama (1859) que demandaron niveles de autonomía e inversiones por las rentas de la minería (Illanes, 1992), se establece una suerte de modelo de cooptación que se indagará en tres coyunturas históricas:

a.- La apertura liberal con amnistía a los federalistas y recuperación de los municipios, que inicia el presidente Pérez tras la guerra civil de 1859. Luego de la derrota federalista y de la tesis de asamblea provincial autónoma de José Miguel Infante (Salazar 2006, Valenzuela E., 2008), se impone el gobierno centralizado que suprime la autonomía regional e incluso los municipios, replicando el modelo monárquico-borbónico de la delegación por sobre los espacios de libertad que había construido el cabildo (Del Alcázar, 2006; Valenzuela, E., 1999). La dureza de los decenios conservadores es resistida en el 1848 chileno, los clubes de la igualdad y la libertad, Bilbao y Arcos, para luego irrumpir con fuerza en el levantamiento de 1851 que une a liberales, reformistas y federalistas (Vicuña Mackenna, 1989), incluyendo la participación de nuevas capas sociales —artesanos, pequeños agricultores y profesores - en experiencias como San Felipe y la toma de Talca (Daitsman, 1995).

Los hechos se agravaron en 1859 con la declaración de la Atacama autónoma y constituyente, el Ejército libre del norte, los tormentos públicos dictados por el intendente y el cansancio de los mineros de financiar incluso el tren a Caldera, ante la indolencia y centralismo capitalino (Bahamonde, 1977). El gobierno central los aplasta y al menos gana en la elite de poder una figura moderada como Pérez, quien realiza la apertura liberal en el decenio de 1860, la cual no repone la Asamblea Provincial Autónoma. Sin embargo, al 
menos regresan los municipios y se inician reformas políticas de mayor libertad de prensa y reunión, incluyendo Ley de Amnistía para los cabecillas Pedro León Gallo y Manual Antonio Matta, quienes se integran al sistema de la mano del Partido Radical, sin cambios de fondo al régimen oligárquico (Vitale, 1971). Los sublevados abdican de la petición de autonomía y se hacen parte del nacionalismo liberal centralista. Los conservadores promueven el municipalismo (Illanes, 1993) como respuesta — Ley Irarrázaval de 1891—, sin regiones fuertes, en la posterior guerra civil contra Balmaceda: municipalismo y parlamentarismo, sin gobiernos regionales, fue la respuesta hasta 1925.

b.- El desarrollismo industrial de las regiones en el Frente Popular como respuesta a la crisis del Estado oligárquico. La crisis del régimen oligárquico de 1924, la dictación de leyes sociales, el auge y caída del alessandrismo y el ibañismo, la depresión mundial agravada con la sustitución del salitre, acompañado de los experimentos socialistas de 1932 en un escenario político muy similar al actual, concluyen con una salida democráticocentralista e industrialista: el Frente Popular integra en alianza al PR-PS-PC de origen metropolitano y solo a algunos de los grupos contestatarios locales, especialmente líderes regionalistas de Magallanes. En la Enciclopedia Chilena, preparada por la Biblioteca Nacional (BN, 1972), se le considera "circunstancial" al Partido Regionalista de Magallanes, organizado solo en su región y vinculado a otros pequeños partidos que reclamaron descentralización: el Federalista y el Agrario. Sus raíces provienen de las protestas de Punta Arenas contra impuestos aduaneros en 1910, que se intensifican en los años 30, uniéndose al auge socialista de 1932 y los movimientos regionalistas que luego aportan al derrocamiento del gobierno de Dávila. Sus líderes se dividen; una parte se incorpora al Frente Popular con la fuerte presencia socialista en la zona, y otros se hacen aliados de facciones de la derecha que asumen un discurso prodescentralización, apoyando en 1952 al candidato Arturo Matte.

En la historiografía hay quienes resaltan que el nuevo Frente Popular desde 1938 respondió a la división derechista y al corrimiento a la izquierda del Partido Radical (Moulián, 2009), iniciando el tiempo de una república democrático-centralista con políticas sociales, pero con alta centralización (Salazar, 2006). La visión regionalista remarca que movimientos como el magallánico empujaron hacia una visión más integral del territorio, con inversiones en zonas mineras para industrializar y por políticas hacia zonas extremas (Martinic, 1992). Es así como vendrá un ciclo de mayor inversión pública y polos de desarrollo — como el acerero en Concepción-, pero sin fondos autónomos ni puesta en funciones de la “asamblea provincial" establecida en la Constitución de 1925, mas nunca reglamentada y tampoco demandada.

La izquierda, inspirada en el modelo francés y luego bolchevique, se hace estatista y no valora la dispersión del poder; más bien recela de la descentralización como un instrumento oligárquico al servicio de latifundistas que con clientelismo controlan municipios y no cree en los territorios. No obstante, los parlamentarios de centro (radicales y demócrata cristianos), al igual que muchos izquierdistas, replican las prácticas liberales-conservadoras de "gestionar proyectos" para "sus comunidades", sin visión de descentralizar y crear fondos autónomos. Se consolida el modelo portaliano que culmina instalando su símil del 
parlamentario broker del poder que lleva las demandas de sus territorios a Santiago, es leal con la coalición oficialista la que, a cambio de su lealtad, le entrega la potestad del copamiento clientelar del Estado y el uso discrecional de los fondos públicos (Valenzuela A., 1977).

c.- Repartición de renta en el retorno regionalista post-pinochetista: un esfuerzo inicial de Aylwin por democratizar los gobiernos locales y dotar de un marco legal a los gobiernos regionales, que va dando paso a la cooptación con beneficios específicos en los gobiernos posteriores a Pinochet del 2000 al 2011. Sectores regionalistas de la Concertación son minoritarios. Luego en el gobierno de la Alianza por Chile estallan los conflictos en Magallanes, Aysén y Calama, donde se repite el modelo de represión, negociaciones pragmáticas, sin autonomía relevante y con intendentes que se ponen de lado del poder central y son los primeros fusibles en quemarse.

\section{El origen en la larga noche portaliana}

Una de las riquezas patrimoniales de la cual se vanagloriaban en el Campus Lircay, de la Universidad de Talca allá por 1985, era la placa conmemorativa ubicada en esos terrenos que rezaba "en este lugar Chile derrotó a la anarquía". En plena dictadura, la manipulación de la historia nacional se elevó a tarea de Estado y así lo asumió la Junta. No eran pocos los aprendices de Clío que por entonces creían, sinceramente, que ella se restringía a una larga lista de confusos héroes, efemérides y batallas sin gloria. No eran menos, también, los docentes que impartían la disciplina y que aún dividían al gremio de los especialistas entre O'higginistas y Carrerinos. En aquel tiempo, solo la presencia de Julio Pinto, y su enfoque de la historia como proceso, llenaba el vacío y el tedio de ese desolado paramo que, luego, enriqueció, también un joven polemista llamado Alfredo Jocelyn-Holt.

Como podrá sospecharse, los alumnos de entonces asimilaron poco de esa historia y tempranamente aprendieron el truco de leer (aunque estuviese prohibido) el Manual de Frías Valenzuela, lo que resultaba suficiente para pasar de curso y dedicarse a cosas más entretenidas como estudiar a Edward Carr, la escuela de los Annales y merodear a Foucault.

Cuando varios de ellos iniciaron sus posgrados, a inicios de los 90, hubo que releer todo de nuevo y, respirando el polvo solemne de los manuscritos del Archivo Nacional, se percataron que les habían contado la historia reversa de lo que realmente sucedió en Lircay. En esos campos, el 17 de abril de 1830, Chile no derrotó la anarquía, más bien sucedió todo lo contrario: la destrucción del incipiente país variopinto que los actores de la Independencia habían querido construir. Una patria inclusiva; en definitiva, un Chile con personalidad regionalista. Un relato epocal testimonia así la masacre de la que fue objeto el bando liberal-federalista:

Era la noche y entre la nube oscura, lentamente su carro dibujaba la plateada luna. La natura tranquila reposaba, el silencio espantoso de la muerte por el 
campo reinaba... ¡O bárbaro rigor! La parca fiera descargando en Lircai su guadaña a los héroes más grandes escogiera para saciar su saña. Yo la vi toda en polvo, en sangre humeando correr por la campaña... ¿Qué esto? ¡Justo Dios! ¿Los vencedores de Chacabuco y Maipú están sin vida y alientan la rabia los traidores? ¡O lucha fratricida! ¡O destino implacable!; ¡Injusto Marte! La razón fue abatida, y alzó la tiranía su estandarte. ${ }^{7}$

El más de medio millar de muertos y los cadáveres pudriéndose en las explanadas de esa colina eran el crudo testimonio de que la larga noche portaliana llegaba para quedarse y la generación de la Independencia era reemplazada por la fronda iniciándose la construcción de un orden oscurantista que persigue y esclaviza a las regiones hasta hoy. El violento orden portaliano.

Luego de Lircay, el bando pelucón o vencedor, encarga al Estado la función de cargar sobre su espalda la responsabilidad del control y el disciplinamiento social; es la misma institución la que intentará, desde ahora, armar un país uniforme e hipócrita: discurso moralista de día y chinganas de noche para las autoridades. Los viejos y eternos aliados de la oligarquía conservadora -delincuentes y bandoleros- se tornan peligrosos y son ahora un verdadero obstáculo para el orden nacional. No es casual entonces que desde inicios de 1830 se tienda el cerco a la delincuencia y en especial al bandolerismo usado y abusado siempre en nuestra historia nacional por esa oligarquía; y se asesine, expulse o confine a los próceres independentistas que quisieron construir un Chile más heterogéneo

El corsé de nuestra propia era victoriana será la Constitución de 1833, que instala -como lo diría Portales- "una monarquía pero sin rey", con un Presidente con facultades exclusivas para dictar estados de excepción; se impone la censura y se llega a obligar a los funcionarios públicos a presentar cargos contra los medios periodísticos que los acusan, so pena de ser encontrados culpables por dicha calumnia ("el que así no lo hiciere, queda suspenso de hecho en el ejercicio de su empleo, y el fiscal le acusará con el mismo impreso ante el tribunal competente"), siendo el esfuerzo final de la psicosis portaliana ese proyecto de ley que permitía allanar las casas, incluso de noche, por orden de cualquier autoridad, agentes de policía, serenos o cualquier persona (Ortiz, 1996).

Un sistema electoral donde el $51 \%$ se llevaba todos los cupos a elegir, la designación de alcaldes y la reelección presidencial completaban un modelo que, en nombre de una democracia censitaria, culminaba instalando una dictadura perfecta. Concluía, aquel estereotipo -que operaba con lógica "del peso de la noche" ("la tendencia casi general de la masa al reposo es la garantía de la tranquilidad pública")-, con el uso en provincias de una figura que databa de la era borbónica: los intendentes, a quienes las más de las veces, por mecanismos extraconstitucionales, y después bajo el amparo de la Constitución de 1833, se transformó en agentes directos del Presidente de la República, designados por él, responsables ante él y dedicados a cumplir sus órdenes, tradición que se mantiene vigente,

\footnotetext{
${ }^{7}$ Anónimo, "Oda a la batalla de Lircay”; Archivo Nacional, 1831.
} 
aunque hoy el cargo depende más bien del parlamentario broker más influyente de la coalición gobernante. Y con la honrosa excepción de Francisco Huenchumilla ${ }^{8}$, continúan siendo iguales a sí mismos: en todos los conflictos regionales, siempre se ponen del lado del Ejecutivo y son, por eso mismo, los primeros fusibles en quemarse cuando estallan los conflictos.

Bajo ese panorama no fue antojadizo que un historiador del siglo XIX, como fue el rancagüino José Victorino Lastarria, que caracterizara a Portales el cerebro de la restauración conservadora que impidó el avance social de Chile y el desarrollo de los territorios (Lastarria 1868).

\section{La figura del Intendente-delegado: De los Borbones a Lagos y Piñera}

"En breve tiempo fue Portales un potentado que tenía a sus órdenes i escalonada en todo el país una falange de guardias i espías" (José Victorino Lastarria).

Como ya se manifestó, la figura del Intendente borbónico ("los ojos y oídos del rey en la provincia"), fue rescatada por la Constitución de 1833, instalándose este arquetipo colonial bajo la dependencia exclusiva del Presidente de la República que no solo sería objeto del desprecio del mismo Portales sino también flanco permanente de la oposición en el Congreso por su intervencionismo electoral a lo largo de todo el siglo XIX.

Si se revisa el debate de las cámaras legislativas de la centuria decimonónica, dicha institución será objeto periódicamente de crítica de parte de los parlamentarios liberales, debido al peso decisivo que ellos desempeñaban en los procesos electorales donde se elegían legisladores por el sistema de lista única y en que el vencedor se llevaba el total de los cargos a llenar. Eran los tiempos en que, más que recurrir a los electores, los postulantes al Congreso apelaban al gran elector (el Presidente) para ser incluidos en la lista oficialista y alcanzar así un escaño.

Portales, el ministro omnipresente caracterizaba del modo siguiente a los jefes-delegados en las provincias:

Ni en esta línea ni en ninguna otra encontramos funcionarios que sepan ni puedan expedirse, porque ignoran sus atribuciones. Si hoy pregunta usted al Intendente más avisado, cuáles son las suyas, le responderá que cumplir y hacer cumplir las órdenes del Gobierno y ejercer la subinspección de las guardias cívicas en su respectiva provincia. El país está en un estado de barbarie que hasta los Intendentes creen que toda legislación está contenida en la ley fundamental, y por esto se creen

\footnotetext{
${ }^{8}$ Destacado político DC que ha sido alcalde, Intendente y ministro de los gobiernos de la Concertación y que, siendo intendente de la Araucanía, durante la actual administración, tuvo gestos de empatía con el mundo mapuche y de autonomía frente al gobierno central lo que le valió ser destituido por su camarada falangista Jorge Burgos, ministro del Interior.
} 
sin más atribuciones que las que leen mal explicadas en la Constitución" (Carta a Joaquín Tocornal, 16 de julio de 1833).

En otra ocasión este es el consejo que le entrega al recién designado intendente Miguel Dávila: "El plan de conducta único que puedo y debo señalar a usted, es el siguiente: cumpla escrupulosamente con las obligaciones de su cargo".

Además, en carta de felicitaciones al intendente de Aconcagua, Fernando Urízar Garfías le agradece: "Por aquella parte de su conducta ministerial que se ha puesto en mi noticia, le voy descubriendo gobernaderas: que tiene usted la prudencia y la firmeza, y que entiende modo más útil de conducir al bien a los pueblos y a los hombres. Palo y bizcochuelo, justa y oportunamente administrados, son los específicos con que se cura cualquier pueblo, por inveteradas que sean sus malas costumbres" (Santiago, abril de 1837).

En otra epístola, irreproducible por los garabatos que expresa, manifiesta su desprecio absoluto por dicha autoridad que solo se sustenta en una facultad presidencial. Si a O’Higgins se refirió como "el huacho maldito" o Don Beño, no cuesta mucho poder imaginarse cómo calificó a los intendentes, a quienes no encontró mérito sino el de responder verticalmente a Palacio y hacer el trabajo sucio en elecciones.

En la república autoritaria, el intendente no resultó ser otra cosa que un ojo espía del monarca en la provincia, que manejaba los asuntos locales a diestra y siniestra en función de los designios metropolitanos. Ello, más la designación vertical de los alcaldes, hicieron posible los decenios presidenciales de Prieto, Bulnes, Montt y Pérez y que hoy quieren repetir Lagos y Piñera.

Como se sabe, además, el portalianismo obligó a los protagonistas públicos a deambular entre la marginalidad (José Miguel Infante) y la cooptación a la que no solo sucumbió Manuel Antonio Matta sino también casi todos los actores políticos de aquella centuria que quisieron desempeñar roles relevantes en esa república, de allí los reclamos permanentes de los diputados díscolos -Matta, Gallo, etc.- a la figura del intendente que, luego de la guerra civil de 1891, dominaron para sí a través del modelo broker -el parlamentario transa sus votos con La Moneda a cambio de la influencia local en el copamiento del Estado y del manejo con fines privados del dinero público-, patrón que, como sabemos, llegó al paroxismo con la reinstalación democrática de 1990 y que tiene a regiones, como la de O’Higgins, con la friolera cifra de 13 intendentes en apenas 15 años.

Tal modelo - combinación de presidencialismo autoritario y centralista, con intendentes designados-, generó el Chile hipercentralizado que los recientes informes de la OCDE han descrito como los obstáculos del país para alcanzar el desarrollo (Ocde, 2009), mal ejemplo que pesa sobre nosotros y que, como se ha dicho hasta la saciedad, el único país de ese grupo que no elige a sus autoridades regionales y que hizo de Santiago, en especial desde Plaza Italia hacia arriba, una capital europea invivible, mientras en el resto de las provincias las ciudades se mantienen y parecen urbes coloniales rezagadas, condenadas al atraso y la 
marginalidad. Parte de esa herencia autoritaria la recogió la izquierda surgida en torno a la crisis de 1930 que refrendó el modelo portaliano y lo hizo suyo.

\section{La pesada herencia portaliana hoy}

Con ese escenario histórico de fondo, no resulta casual que hoy el piñerismo autoritariocentralista (la UDI y un sector de RN) y el laguismo borbónico no quieran elegir al gobernador, como tampoco es accidental que ambos ex presidentes, como en la república conservadora donde el intendente era su interventor, quieran emular a sus referentes dieciochescos y alcanzar su propio decenio.

Así como la Corona hizo recaer sobre los mapuche el peso de la interdicción -eran niños que no podían representarse jurídicamente a sí mismos-, la república oligárquica hizo caer sobre las antiguas provincias, devenidas hoy en regiones, el mismo estatuto: no somos aptos para elegir a quien gobierne la región, dándose la paradoja de que podemos elegir desde la junta de vecinos hasta el parlamentario broker, pero no a quien gobierne el territorio.

El Senado y una maltrecha coalición gubernamental que, desde 1990 en adelante, sobre este tema solo ha practicado la corrupción programática, tienen la última palabra. El 5 de octubre se dio un paso histórico para sacudirse del mito de Lircay y de la historia reversa, pero aún falta.

Las excusas del piñerismo portaliano -en especial la UDI y su conexión ancestral con la violencia y el autoritarismo- son incluso atendibles, dada la pesada carga histórica de la Hacienda y la cultura del latifundio entre sus huestes. Hasta se comprende en Piñera - poco dado a la generosidad y a la distribución del poder con los otros- y su intención, como Prieto, Bulnes y Montt, de alcanzar su propio decenio conservador. Sin embargo, se entiende mucho menos en el laguismo (aun a sabiendas de su admiración declarada por el Presidente más autoritario del siglo XIX), y su entorno -Harboe, Lagos Jr. y Carlos Montes-, dado que alguna vez, en su versión progresista (Crecer con igualdad), prometió elegirlos y hasta le inventó una región a su amigo el ex senador Fernando Flores.

Es tiempo de acabar en regiones con la figura más recalcitrante y degradada heredada del borbonismo déspota y del autoritarismo portaliano, así como, también, poner fin a la historia de Chile que se escribe desde la metrópolis y que solamente se reconoce en ella.

A comienzos del nuevo siglo, se constituye el grupo los Federales, rescatando la versión autonomista del regionalismo, quienes politizan los movimientos regionalistas y académicos provincianos con la demanda de elección de autoridades (Martelli et al., 2002). A su vez, durante toda la segunda década de gobiernos de la Concertación, y durante los dos primeros años del gobierno de Piñera —Alianza — se suceden protestas regionalistas demandando identidad regional (Arica y Valdivia), regalías por sus recursos (Antofagasta- 
Calama), planes ante la pobreza y cesantía (zona del carbón, Atacama, Illapel), subsidios a los altos costos de energía y transporte en zonas extremas (Magallanes, Aysén).

La Concertación no logra realizar reformas electorales, por el rechazo de la derecha bajo un marco constitucional de altos quórums para leyes orgánicas, pero tampoco realiza reformas descentralizadoras en este caso, porque la centroizquierda es dominada por una lógica de control del aparato estatal con sello paternalista y de distribución de cuotas de poder, asumiendo el modelo presicrático del constitucionalismo pinochetista (Salazar, 2011; Valenzuela, E., 2008). Por su parte, en la derecha hay una división entre la UDI, que defiende el modelo de delegación en las regiones y reduce la descentralización al municipalismo, y segmentos de Renovación Nacional que propician reformas políticas y proponen con la Democracia Cristiana en el año de las protestas estudiantiles (2011), la mayor reforma política en medio siglo: semipresidencialismo con poder parlamentario y elección de gobiernos regionales. Estos dos elementos — protestas regionales y propuestas descentralizadoras desde las elites - hacen nominar a esta coyuntura el "retorno del regionalismo".

\section{El debate hoy: la pugna izquierda comunalista/regionalista versus el bonapartismo de la nueva burguesía fiscal}

Crecientemente la autonomía territorial y modelos socio-políticos descentralizados recuperan vigencia entre intelectuales y movimientos de la izquierda chilena. El ex diputado por Linares, Alejandro Bell fustigó la descentralización formalista y adelanta que el propio conflicto mapuche no tiene salida sin esta reforma: "El Estado Unitario ha bloqueado persistentemente toda posibilidad efectiva de regionalización. Y no existe regionalización si no hay poder regional tanto político, económico como institucional. La actual situación en La Araucanía ha vuelto a poder en relieve, de manera dramática, esta indispensable transformación del Estado" (Bell, 2010: 8-9).

A la línea argumentativa que explica el centralismo en la mentalidad absolutista que se hereda de la Corona Española en la forma de los caudillos militares y el presidencialismo fuerte (Véliz 1984), que en el caso de Chile se naturaliza por el consenso en la elite en favor del modelo presicrático de presidencialismo con centralismo (Valenzuela 2007), se suman trabajos más recientes que lo ligan a un ethos autoritario que se refuerza en la cultura de la hacienda donde se "teme a los subordinados" y por tanto en vez de pactar socialmente se le controla y reprime (Araujo 2016).

Para transformar el oscuro panorama descrito han sido claves la reconstitución en Chile de una izquierda comunalista/regionalista y con algunos ribetes federalistas que ha sido capaz de cuestionar la combinación de neoliberalismo con centralismo que predomina en el modelo chileno. Es una izquierda que se conecta en la común lucha de las regiones por la autonomía territorial versus la implacable maquinaria represivo-cooptadora del centralismo chileno histórico (Valenzuela 1999). Como ya lo dijimos durante siglo y medio tras la imposición del autoritarismo centralista portaliano en la constitución de 1833, los intelectuales y grupos federalistas fracasaron en el siglo XIX en su intento por construir un 
Chile más variopinto y ello se expresó en la marginalidad de José Miguel Infante y la incorporación al poder abandonando la demanda de provincia autónoma en que incurrieron los fundadores del Partido Radical e instigadores de la Revolución de 1859 en Copiapó, Pedro León Gallo y Manuel Antonio Matta (Ortiz y Valenzuela 2014). Luego Recabarren fue infatigable hacia el 1900 en la lucha por la construcción de poder obrero y popular desde los territorios del norte y la actividad mancomunal (Valenzuela, 1999, Salazar 2012). Sin embargo, esta tradición comunalista y territorial se desdibuja con los partidos nacionales (Radical, Comunista, Socialista) que aspiran a la construcción de reformas nacionales desde el triunfo del Frente Popular en 1938 y la cooptación que sufrió el Partido Regionalista de Magallanes en los 1940s. Así se consolida un silencio de las izquierdas en las luchas territoriales en el ciclo de reformas "nacionales" de Frei y Allende. Recién se reactivan movimientos de izquierda federal o territorial a mediados de los 1980s en medio de la dictadura y la revalorización de lo local y la resistencia mapuche.

Sabemos que, contra su discurso, la concertación luego de un impulso local hacia el fortalecimiento de los poderes locales - municipios y gobiernos regionales - desde Frei en adelante viró, pese a su discurso, hacia mayores niveles de consolidación de centralismo y hegemonismo metropolitano. Recién con la segunda candidatura de Michelle Bachelet y la constitución de la Comisión Asesora Presidencial en Descentralización y Desarrollo Regional (2014) que enarboló un conjunto de propuestas, algunas de las cuales se trasformaron en proyectos de ley - entre ellos la elección del Gobernador regional -es que la agenda gubernamental vuelve a poner el tapete el problema de la desigual e ineficiente distribución del poder.

Y hoy duele observar, como se evidenció en el debate por la elección de gobernadores, que buena parte de la dirigencia de izquierda chilena actuaba como paladines del centralismo, del poder burocratizado y de la domesticación de actores territoriales. Posturas en las antípodas del ideario libertario y descentralizador de las grandes izquierdas transformadoras, las mismas que en Escandinavia, Cataluña o Uruguay, hacen de la dispersión del poder y de su devolución a los pueblos y comunidades que habitan el territorio, un aspecto esencial de su programa. De hecho, los países más avanzados y equitativos del mundo, los socialistas democráticos de Suecia, Noruega y Dinamarca, tienen una larga tradición de poder municipal, regional y autonomías a sus pueblos originarios (esquimales y lapones o samis). Nada de miedo a las comunidades. De dicha tradición se nutrió el Frente Amplio uruguayo, haciendo de la gestión de Montevideo un paradigma de gobierno participativo y progresista, creando además municipios complementarios a nivel macrodepartamental. Son la izquierda republicana catalana y los socialistas ibéricos que, a diferencia de la derecha, no temen a las autonomías o al "arreglo federal'".

En Chile la izquierda tradicional no se entusiasma con la descentralización y salvo algunas grandes excepciones, como las voces regionales en Magallanes, el Norte, Concepción, y segmentos del centro que han apostado desde hace años por un socialismo que profundiza 
la democracia y no su concentración en un puñado de aristócratas e intermediarios del poder en Santiago, ésta sigue siendo burocrática y clientelar. Resultó pavoroso el tibio apoyo a la elección de Intendentes, las mil razones para postergar los procesos, el predominio de la construcción de más agendas estatales por sobre el empoderamiento autónomo de las regiones, incluyendo las áreas metropolitanas.

Es el tiempo en que el PS - que desde su conferencia de Organización y Programa de 2001 apostó por la elección de intendentes, aunque luego no realizó ningún esfuerzo mayor por implementarla -y otras fuerzas progresistas históricas, en relación al discurso sobre la descentralización administrativa, política, económica y cultural, sean protagonista y no apéndice de su plataforma. Descentralizar es un proceso ineludible para las naciones que quieren ser cohesivas en el contexto de la globalización. Recabarren fue un precursor y un vivo ejemplo de una izquierda comunalista y regionalista, a diferencia de aquella que sólo quiere administrar el "Palacio de Invierno": regidor del Partido Demócrata, constructor de movimiento social desde abajo con las mancomunales y la ayuda mutua fraterna entre el mundo de los trabajadores(as) del norte, diputado del Partido Obrero Socialista, luego Comunista en su congreso en Rancagua. Recabarren cuando escribió el ya citado texto "lo que puede hacer un pueblo inteligente" en el poder local y antes de morir advirtió los peligros autoritarios que amenazaban la propia izquierda que había ayudado a construir.

Jorge Arrate en los 1980s escribía que el socialismo era la materialización del ideal democrático, y la democracia es la distribución del poder en muchos. El doctor Edgardo Condeza, en Concepción, pide asamblea constituyente, plebiscito y regionalismo. Eduardo Cifuentes, desde el sur, sigue creyendo en las escuelas de formación y en las redes de los emprendedores campesinos desde su comarca. Adolfo Millabur demuestra el virtuosismo del poder lafquenche para señalar otros caminos de desarrollo. La Presidenta Michelle Bachelet rompe con 180 años de centralismo institucional y devolverá a las provincias y regiones el derecho a elegir su Intendente. Son voces de una corriente socialista transformadora que hace del poder de las comunidades y de los territorios el motor de la historia. La izquierda tradicional no puede restringirse solo a administrar el Estado y constituirse solo como una nueva Burguesía Fiscal a la que, exclusivamente, le interesa vivir del presupuesto público y de los contratos que se derivan de la administración del Estado.

En efecto, por debajo de las grandes frases y titulares se develó, en especial a inicios de esta administración bacheletista, como expresión de un nuevo conjunto de intereses un nuevo grupo social. Decimos esto porque, en el contexto de las nominaciones, salió a la luz pública la naturaleza y composición del nuevo equipo de gobierno. Así como Sebastián Piñera representó en el gobierno sobre todo al 1\% más rico de Chile, a sectores liberales de la elite y al mundo de las clases medias y populares conservadoras, Bachelet con su retorno a La Moneda pareció encaminarse a consolidar en la administración pública una amplia alianza de intereses - que desde luego ha hecho muy difícil su gestión política-, pero que incluye, junto con una continuidad del pacto con el gran empresariado que en su anterior 
gobierno personificó Andrés Velasco y hoy se expresa en los vínculos de ministros clave, como los de Hacienda, Economía y Energía, con poderosos intereses corporativos, a una burguesía emergente de nuevo cuño. Es aquella a la que le encanta vivir cerca del Presupuesto para ganarse la vida. "Esa astuta y sensata pequeño burguesía", decía uno de los personajes de Vida y Destino, cuando se refería a los nuevos funcionarios del PCUS que habían ascendido al poder tras las purgas de 1937 (Grossman, 2001).

La cultura concertacionista generó una trama de operadores y control desde las facciones con mayor peso en La Moneda (Valenzuela 2015). Constituyeron entonces cofradías desde las cuales tendieron redes, formaron empresas (en especial de asesorías y gestión de servicios subsidiados) y comenzaron a buscar acercamientos y alianzas con el mundo empresarial tradicional, especialmente el que depende de actividades con fuerte regulación pública.

La nueva burguesía que ha crecido al alero fiscal y sus noveles representantes políticos en la primera línea, tiene su origen en la clase media. A diferencia de muchos de los políticos tradicionales, tienen escaso currículo académico, no se les conoce escrito alguno, pero saben cómo funciona 'la máquina estatal' y los partidos, lo que les resulta de utilidad. No son líderes históricos partidarios, ni hicieron el servicio militar en la colectividad en el trabajo social o de base. Su ascendencia sobre la militancia es de otra naturaleza: es la que proviene del cuoteo en el Estado, en lo que se han especializado desde jóvenes cuando, al alero de sus padrinos, familiares o parejas, aprendieron y perfeccionaron la técnica. Son, en general, de relativamente bajo perfil y de hecho varios de ellos prefieren influir a través del aporte voluntario a las campañas más que desde sus directivas. Y si bien son otras las caras visibles de la nueva coalición de gobierno, es este nuevo grupo de poder quien manda cada vez más en la Nueva Mayoría. Mientras, los partidos como instituciones miran desconcertados la reconfiguración del poder gubernamental y su poca incidencia en las definiciones futuras, salvo los que entre sus miembros lograron hacerse parte de las tramas del "bacheletismo".

Tal vez la principal característica de esta "nueva burguesía fiscal" y sus asociados políticos sea su hábil manejo de los resortes del poder estatal y su capacidad de tejer redes transversales de influencia, aunque por cierto no tiene la envergadura del gran empresariado ni la importancia de la pyme en la economía y el empleo. En todo caso, se acomodó sin dificultades durante el interregno del gobierno de la derecha y ahora adquiere nuevos bríos con la perspectiva de dominar parte importante de la nueva administración junto a sus representantes políticos cercanos. $\mathrm{Y}$ eso es precisamente lo que quedó en evidencia durante el primer año del actual gobierno. Se supo que no sólo estaban en la primera y segunda línea del Estado, sino también que son parejas de parlamentarios, ex maridos, compañeros, correligionarios o camaradas, también amigos, a la vez dueños de empresas de asesoría o de prestación de servicios subsidiados. La arista Soqumich (SQM) es una evidencia concreta de cómo se desarrolló este fenómeno. Parecen invisibles, pero están en todos lados, al alero de un régimen político híbrido que nunca consolidó uno de los componentes básicos de la democracia: el espíritu de servicio, especialmente entre los 
representantes de los ciudadanos y los directivos públicos, con las consabidas honrosas excepciones. El culto general al "dios mercado" y el individualismo propio de la época han hecho lo demás para permitir un creciente deterioro de la esfera pública.

Es esta izquierda bonapartista que predomina, en especial en el PS-PPD-PC la que hay que transformar y orientarla hacia una vocación más comunalista y regionalista que se atreva más allá de su tradicional tendencia a solo administrar el poder estatal desde la metrópolis.

\section{El modelo chileno de cooptación que fragiliza la constitución de una alianza regional-descentralizadora}

La élite dominante chilena perdió su influjo transformador con la derrota de 1973 para luego, con el retorno democrático, mutar definitivamente hacia la consolidación de lo que se ha denominado el partido del orden que corrigió excesos neoliberales, pero mantuvo el modelo económico y el centralismo político (Valenzuela 2013). Se dio así un caso de convergencia en que el duopolio - ayer concertación y derecha, hoy, Nueva Mayoría y Chile Vamos -o partido transversal con vínculos profundos con el gran empresariado, generó una suerte de homogeneidad social y económica de la elite chilena pasando de ser grupos de funcionales-conservadores a disfuncionales-disruptivos (Alcántara, 2003). Al mirar el fracaso de una alianza transformadora-regionalizadora en la historia de Chile, se observa la existencia permanente de una elite centralista hegemónica que se distribuye de derecha a izquierda para consolidar el modelo centralista que ha debilitado los frentes regionalistas, respondiendo a las crisis con aperturas tibias, repartición de alguna renta y cooptación de líderes. Se pueden emplear desde los clásicos Michels, Mosca y Pareto, pasando por Wright Mills (1957), para ejemplificar que la elite de poder es un grupo que se diversifica, pero mantiene su cohesión sobre la base de sus intereses y creencias fuertes, como en el caso chileno donde predomina el mito, bastante discutible, que el centralismo construyó la estabilidad y que éste le hizo bien al país.

Acuñaremos el término convergencia programática de fondo de la elite de poder, para entender la predominancia en Chile de un orden basado en el Estado central, la supervisión, capitalismo con rentas públicas moderadas y control de niveles de autonomía localregional, el cual se repite en las tres coyunturas históricas. Los elementos del modelo de cooptación centralista del regionalismo que permeó también a la izquierda se reprodujeron por dos razones estructurales.

a.- La lógica dominadora-cooptadora-centralista: represión de los sujetos rebeldes, llamado nacionalista a la unidad del país, discurso sobre las ventajas del centralismo en la creación de mínimos para todos los territorios, anuncios de reformas con comisiones de estudios, soluciones parciales de repartición de renta menor sin leyes estructurales ni autonomía política.

b.- La ausencia de una alianza interregionalista y macroétnica: rebeldía de territorio con liderazgos contenciosos, pliego de demandas parciales, actos de sabotaje y movilización, 
represión y tregua, negociaciones, firma de acuerdos con beneficios parciales e integración de líderes a las estructuras de poder - alcaldías, postulaciones al Parlamento-, incluyendo a veces el olvido del discurso proautonomía territorial en el propio progresismo.

Tanto el mejor nivel de desarrollo de Chile como su "estabilidad", configuran la doctrina de no-reforma en las elites dominantes, donde existe una amplia legitimidad de la visión centralista y homogénea del Estado en Chile, que lleva a diferentes gobiernos a combinar represión-cooptación como modelo para evitar una transformación política mayor de corte regionalista. Los movimientos regionalistas se tensionan entre sus corrientes "reivindicacionistas" - mejoras, regalías, nuevas transferencias - y las "autonomistas", que demandan niveles de autogobierno, dominando a las primeras, que son cooptables con soluciones económicas parciales. Los líderes regionalistas son cooptados por partidos nacionales ante la fragmentación del regionalismo y la ausencia de un partido nacional explícitamente regionalista en su agenda.

El uso del nacionalismo ha servido para acusar intentos cesionistas y aislar la demanda regional, con medidas de integración cultural y homogenización. El presidencialismo exacerbado y un modelo electoral hipermayoritario — binominal - acentúa el rechazo de los parlamentarios a ceder al poder ante entes regionales autónomos (mantención del clientelismo y el brokerage).

En los momentos críticos se anuncian reformas que luego no se realizan (cinismo programático). Por otra parte, la ausencia de partidos regionales lleva a la localización y explosión social y callejera de los conflictos o a la deserción democrática como ha estado sucediendo últimamente. La escasez de alianza entre los distintos movimientos mapuches, alimentada también por la falta de posibilidades de crear partidos y/o plataformas electorales comunales o regionales, ha restado la posibilidad de contar con mayor poder político.

\section{La Propuesta de la Comisión Presidencial y el modelo dual incremental resistido por el partido del Orden: un balance}

La izquierda comunalista y la bonapartista tuvieron oportunidad de encontrarse fundamentalmente en la comisión asesora presidencial para la Regionalización y Descentralización que se constituyó para tal efecto como una de las primeras 50 medidas de la administración Bachelet durante sus primeros 30 días de gobierno. Allí pudo verse la profunda distancia entre ambas.

La comisión que reunió a una pléyade de connotados regionalistas así como a representantes del gobierno, funcionó entre abril y septiembre de 2014 bajo cinco ejes temáticos y llevó a cabo 15 diálogos ciudadanos donde participaron una 4 mil personas habilitándose incluso una página web para recibir propuestas. Todo el trabajo anterior se tradujo en un informe final donde las demandas ciudadanas se expresaron en un sí - se incorporó al propuesta en un $100 \%$-, Parcialmente - se incorporó parte de la propuesta - y No -No se incorpora la propuesta - en el informe final. En general las diversas demandas 
ciudadanas fueron agregadas en el informe final de la Comisión las que, sin embargo, debieron pasar el filtro de 17 votos de un total de 25 votantes reales, lo que ya constituyó un escollo debido a la procedencia heterogénea de sus integrantes y que luego fueron minimizadas en la agenda gubernamental. En general la Comisión aceptó un $76 \%$ de las demandas surgidas en los encuentros ciudadanos; un 11\% parcialmente y otra cifra similar no tuvo recepción alguna por parte del ejecutivo. Distinto fue el derrotero que siguieron las iniciativas en la agenda gubernamental donde solo un $9 \%$ de las propuestas fueron incorporadas como iniciativas legislativas, un $25 \%$ parcialmente, y $11 \%$ están en agenda mientras que un 55\% no tuvo ninguna recepción (Penaglia). En síntesis: se acogió la elección de un ejecutivo regional, no hubo ley de rentas, permiso al endeudamiento regional ni titularidad sobre el agua y los recursos naturales, así como nada de democracia participativa radical.

En ese debate se evidenció nítidamente la fisura entre la izquierda portaliana que se expresó en los miembros de la comisión, en los ministros de Estado que implementaron las medidas para concretizar el cumplimiento de la agenda regionalista y en los propios parlamentarios de la Nueva Mayoría que las votaron luego. También se pudo observar la resistencia a una democratización efectiva de una parte de la izquierda histórica pues las propuestas surgidas desde el trabajo de comisiones y de los más de 15 Cabildos fueron minimizadas primero por el ejecutivo y luego por el parlamento. Un caso emblemático de ese fenómeno y de la disputa entre ambas izquierdas fue la votación por la elección de los gobernadores Intendentes -, que se envió como un proyecto incompleto por el ejecutivo - elección pero sin traspaso simultaneo de recursos ni competencias - donde el hueso más duro de roer estuvo en los propios parlamentarios del mundo PS-PPD, como Carlos Montes, Ricardo Lagos Weber o Felipe Harboe que se opusieron con muchos pretextos, a la devolución efectiva de soberanía a las regiones ${ }^{9}$. Sin embargo, una intensa campaña mediática de regionalistas y de la izquierda comunalista pudo forzar el voto afirmativo de una mayoría del senado para que, con algunos reparos, la moción fuese votada, finalmente, favorablemente.

\section{Conclusión: La activación discursiva regionalista y el asomo de una izquierda pro federalista}

Esta nueva izquierda en proceso de reconfiguración en Chile está compuesta por tres segmentos que convergen en la transformación del Estado centralista con predominio del doble duopolio Derecha- Concertación y mega élite-empresarial lo que quedó develado de manera más categórica en los escándalos 2013-15 con el extendido financiamiento a los partidos y candidatos por parte de dichas corporaciones ligadas a las industrias minera, pesqueras, forestales, AFPs, sanitarias privatizadas, entre otras. Dichos segmentos son a.los movimientos regionalistas y verdes que pujan por modelos alternativos de desarrollo al extractivismo dando a las regiones postestades de control de los bienes comunes (el agua, los recursos naturales, bosques y glaciares) y capacidad de planificación macro territorial vinculante que impidan la aprobación particular de mega proyectos invasivos del habitat b.-

${ }^{9}$ Debate en el Senado de la descentralización en octubre del año 2016. 
el movimiento mapuche que en su diversidad busca poder territorial, autonomía, tierra comunitaria y plurinacional, c.- los diversos segmentos de izquierda extraparlamentarias y disidentes de la Concertación que proponen tanto la democratización del espacio regional, la mayor tributación de las empresas con coparticipación de la renta por recursos naturales, competencias sustanciales que incluyen el rol en el desarrollo económico y control social del poder incluyendo mecanismos de democracia directa.

No obstante la derrota parcial de las propuestas de la Comisión para la Descentralización del año 2014, los cabildos regionales y la creciente demanda regionalista desde los territorios, permitió articular una agenda y un programa que aporta a la creciente hegemonía de ideas de democratización socioeconómica y política en la izquierda chilena, temas hasta el 2000 de minorías proféticas.

\section{Bibliografía:}

- Ai Camp, Roderic (2000). La política en México. México: Siglo XXI.

- Alcántara, Manuel (1997). "El análisis de los diputados latinoamericanos en el contexto de los estudios sobre la clase política”. Revista América Latina Hoy, 16: 15-28.

- _ (2003). "Las Tipologías y funciones de los partidos políticos”. En Curso de Partidos Políticos, editado por Mella, Manuel. Madrid: Akal.

- Amunátegui Solar, Domingo (1928). El cabildo de La Serena. Santiago de Chile: Editorial

Universo.

-Araujo, Kathia (2016). El miedo a los subordinados. Una teoría de la autoridad. Santiago: Lom.

- Bahamonde, Mario (1977). El caudillo de Copiapó. Santiago de Chile: Editorial Nascimento.

- Barría, Jorge (1967). Chile en el siglo XX. Santiago de Chile: ILARI.

- Barros Arana, Diego (1894). Historia Jeneral de Chile. Tomo XIII. Santiago de Chile: RafaelJover, ed.

- Barros, Luis y Vergara, Ximena (1991). "Los grandes rasgos de la evolución del Estado de Chile 1820-1925”. En: Raúl Atria y Matías Tagle (eds.). Estado y política en Chile. Santiago de Chile: CPU.

- Beck, Ulrich (1999). La invención de lo político. México: Fondo de Cultura Económica. 
Bell, Alejandro (2013). "Regionalismo Autonómico: Fundamentos de un Proyecto Estratégico para la Región de Tarapacá. Iquique. Publicaciones Norte Fuerte.

- Benavente, Diego (2008). Descentralización: La Revolución Olvidada. Temuco: Universidad Católica de Temuco..

- Bilbao, Francisco (1988). El evangelio americano. Caracas: Biblioteca Ayacucho.

- Bobbio, Norberto y Matteuci, Nicola (1988). Diccionario de Política. Madrid: Siglo XXI.

-Boisier, Sergio (1989). "Palimpsesto de las regiones como espacios socialmente

Construidos". En: Descentralización del Estado. Véase Laurelli y Rofman Buenos Aires: CEUR.

- _ (1999). "El Desarrollo Territorial”. Revista Estudios Sociales, CPU, Número 99.

- Borja, Jordi (2014). Revolución urbana y derechos ciudadanos, Madrid: Alianza Editorial

- Burns, Nancy (1994). The Formation of American Local Governments. Private values in public institutions. Oxford: Oxford University Press.

- Carrión, Fernando y Ponce, Paúl (2015). El giro a la izquierda de los gobiernos locales de América Latina.Quito: Fes-ildis.

- Castells, Manuel (1997) Local y global. La gestión de las ciudades en la era de la información. Madrid: Taurus.

- Cea, José Luis, (1992) "Presidencialismo reforzado. Críticas y alternativas para el caso chileno", en Oscar Godoy, editor, Cambio de régimen político. Santiago: Ediciones Universidad Católica de Chile.

- Ceamanos, Roberto (2014). La comuna de París (1871). Madrid: Los Libros de la Catarata.

- Collier, Simon y Sater, William (1996). A History of Chile 1808-1994. London-New York: Cambridge University Press.

- Crawford, William (1994). A Century of Latin-American Thought. New York: Praeger.

- Cumplido, Francisco (1992) Análisis del presidencialismo en Chile. En Godoy, Óscar (ed.) (1992). Cambio de Régimen Político. Santiago: Ediciones Universidad Católica de Chile. Pp.21-36. 
- Daitsman, Andrew (1995). "The People Shall Be All: Liberal rebellion and popular mobilization in Chile 1830-1860”. Thesis Ph.D. University of Wisconsin-Madison.

- Del Alcázar, Joan (2006). Historia Contemporánea de América. Valencia, Universidad de Valencia.

- Desanti, Dominique (1973), Los socialistas utópicos, Barcelona: Anagrama

- Abramson, Pierre-Luc (1999). Las utopías sociales en América Latina en el siglo XIX. México: FCE.

- Espinoza, Vicente (2010). "Redes de poder y sociabilidad de la élite política chilena. Los parlamentarios 1990-2005”. Revista Polis 9: 251-286.

- Finot, Iván (2003). Descentralización en América Latina: cómo hacer viable el desarrollo local. Santiago de Chile: ILPES- CEPAL.

- Gandhi, Jeanifer y Przeworski, Adam (2006). "Cooperation, cooptation and rebellion under dictatorships”. En: Economics and politics. Vol. 18. Oxford.

- Gaxie, Daniel (1983). "Les facteurs sociaux de la carrière gouvernementale". Revue Francaise de sociologie 24 (3): 441-465.

- Gerschewski, Johannes (2010). "The Three Pillars of Stability. Towards an Explanation of the Durabili-ty of Autocratic Regimes in East Asia". Paper prepared for the 106th Annual Meeting of the American Political Science Association (APSA), 2-5 September 2010, Washington, D.C.

- Godoy, Óscar (ed.) (1992). Cambio de Régimen Político. Santiago: Ediciones Universidad Católica de Chile.

- Guzmán, Jaime (1992). Escritos Personales. Santiago de Chile: Zig-Zag.

- Garretón, Manuel Antonio (1983). Proceso Político Chileno. Santiago de Chile: Flacso.

- Góngora, Mario (1981). Ensayo histórico sobre la noción de Estado en Chile en los siglos XIX y XX. Santiago de Chile: Ediciones de la Ciudad.

- Haldenwang, Christian (1991). "Hacia un concepto politológico de la Descentralización del Estado en América Latina”. En Programa FAUS: Descentralización y Estado Moderno. Bogotá-FESCOL.

$-$

(1999). "Staatliches Handeln und politische Regulierung: Die Legitimität politischer Ordnungen im 21. Jahrhundert.” In: Politische Vierteljahresschrift 40 (3), 365389. 
- Hunneus, Carlos (2000). El Régimen de Pinochet. Santiago de Chile: Sudamericana.

- Illanes, María Angélica (1992). La dominación silenciosa: productores y prestamistas en la minería de Atacama. Chile 1830-1860. Santiago de Chile: Instituto Profesional Blas Cañas.

- (1993). "El proyecto comunal en Chile (Fragmentos): 1810-1891”. En: Revista Historia, Vol. 27. Santiago, Instituto de Historia, Pontificia Universidad Católica de Chile.

- Jaksic, Ivan (1989). Academic Rebels in Chile. New York: State University of New York.

-Jara, Alvaro (1971). Guerra y sociedad en Chile. Santiago, Editorial Universitaria.

- Jocelyn-Holt, Alfredo (1997). El peso de la noche. Buenos Aires: Ariel.

- Joignant, Alfredo y Guell, Pedro (ed.) (2011). Notables, Tecnócratas y Mandarines. Santiago de Chile: UDP.

- Jordán, Pablo (1994). "La descentralización: un proceso en desarrollo”. En: Luis Larraín (ed.). Chile Hacia el 2000. Santiago de Chile: CEP. 1994

- Joseph M. Gilbert (1980). “Caciquismo and the revolution”. En: Caudillo and Peasant in the Mexican Revolution. DA S. BRading(ed) Reino Unido: Cambridge University Press

- Lastarria, José Victorino (1968). La reforma política. Santiago: Libertad.

- Laurelli, Elsa y Rofman, Alejandro (ed.) (1989). Descentralización del Estado. Buenos Aires: Fundación Ebert y CEUR.

- Lewis, Stephen E. (1994). "Myth and the History of Chile's Araucanians". Radical

History Review, 58. US.

- Lipp, Salomon (1975). Three Chilean Thinkers. Montreal: McGill University.

- López Murphy, Ricardo (1995). La descentralización fiscal en América Latina:

problemas y perspectivas. Buenos Aires: BID.

- Marimán, José (2012). Autodeterminación. Santiago de Chile: LOM Ediciones.

- Martelli, Giorgio, Benavente, Diego y Valenzuela, Esteban (2002). El Fantasma Federal en Chile. Santiago de Chile: FES-Universidad de Rancagua.

- Martinic, Mateo (1992). Historia de la Región Magallánica. 2 tomos. Punta Arenas: Universidad de Magallanes.

- Martin, Gastón (1945). Les Jacobins. Paris: PUF. 
- Martner, Gonzalo (1993). Descentralización y modernización del Estado en la transición. Santiago de Chile: LOM Ediciones.

- Medellín, Pedro (1994). La modernización del Estado en América Latina. Entre la reestructuración y el reformismo. Bogotá: CIDER.

- Medina, José Toribio (1897). Colección de Documentos Inéditos para la Historia de Chile. Tomo XIII: Valdivia y sus compañeros. Santiago de Chile: Imprenta Elzeviriana.

- Messner, Dieter (1996). Latinoamérica hacia la economía mundial: Condiciones para el desarrollo de la competitividad sistémica. Buenos Aires: Prosur, FES.

- Molina, Miguel (1996). El Municipio en América: su desarrollo histórico. Granada: CEMCI.

- Moulián, Tomás (1993). La forja de ilusiones: El sistema de partidos 1932-1973. Santiago de Chile: Arcis-Flacso.

$-$ (2006). Fracturas: de Pedro Aguirre Cerda a Salvador Allende (1938-1973). Santiago de Chile: LOM Ediciones.

$-$ (2009). Contradicciones del desarrollo político chileno, 1920-1990. Santiago de Chile: LOM-Arcis.

- Morris, Arthur y Lowder, Stella (1992). Decentralization in Latin America. New York: Praeger.

- Nickson, Andrew (1995). Local Government in Latin America. Boulder, CO: Riemer.

- Newton, Michael y Donaghy, Peter (1997). Institutions of Modern Spain. A Political and Economic Guide. Cambridge: Cambridge University Press.

-Ortiz, Edison (1996). "La penitenciaria: otra aproximación a la modernidad chilena decimónónica. Revista última Década, $N^{\circ}$ 6, Cidpa, Valparaíso.

- Ortiz, Edison y Valenzuela,Esteban (2014). "Infante y Matta: entre la disidencia y la cooptación. El fracaso del federalismo en el siglo XIX”.Cuadernos de Historia n.41, pp.732.

-Penaglia, Francesco (2016). Subversión del orden transicional. Del oscurantismo postdictatorial a la esperanza. Santiago. Editorial El Buen aire S.A.

- Pinto, Jorge (1983). La Serena colonial. Valparaíso: Universidad Católica de Valparaíso.

- Preciado, Jaime y Uc, Pablo (2010). "La(s) autonomía(s) en América Latina: Una expresión socio-espacial del Estado novísimo y sus efectos en el proceso de integración regional". Reveu Orda 214: 199-220. 
- Putman, Robert (1993). Making Democracy Work: Civic Traditions in Modern Italy. Princeton, NJ: Princeton University Press.

- Ramírez, Hernán (1972). Balmaceda y la contrarrevolución de 1891. Santiago de Chile: Editorial Universitaria.

- Rehren, Alfredo (1992). "El gobierno local en la ciencia política”. Política 29. Santiago.

- Rousseau, Mark (1987). Regionalism and Regional Devolution in Comparative Perspective. New York: Praeger.

- Restrepo, Darío (2008). "El Eslabón Perdido de la Descentralización en América Latina". En: Descentralizar, un derrotero a seguir. Quito: Flacso-inWent-SENPLADES.

- Rosales, Mario (2012). Descentralización del Estado y Finanzas Municipales en América Latina. Santiago: Flacma-Universidad Bolivariana.

- Smith, Peter H. (2005). Democracy in Latin America: political change in comparative perspective. Oxford: Oxford University Press.

- Salazar, Gabriel (2011). En el nombre del Poder Popular Constituyente. Santiago de Chile: LOM Ediciones.

$-$ Santiago de Chile: LOM Ediciones.

(2006). La violencia política popular en las "Grandes Alamedas".

- _ (2005). Construcción de Estado en Chile (1760-1860): democracia de "Los pueblos" militarismo ciudadano golpismo oligárquico. Santiago de Chile: Editorial Sudamericana.

$-$

(2000). La sociedad civil popular del poniente y sur de Rancagua. Santiago de Chile: Ediciones SUR.

$-$ (1995). "Municipio popular y construcción del Estado: El pensamiento de L.E. Recabarren". Revista de Sociología, 6. Santiago.

- Santa María, Domingo (1902). Vida de Don José Miguel Infante. Santiago de Chile: G. Miranda Editor.

- Valenzuela, Arturo (1977). Political brokers in Chile: local government in a centralizad polity. Durham: Duke University Press.

- Valenzuela, Esteban (1999). Alegato Histórico Regionalista. Santiago de Chile: SUR.

$-$ (1998). "Adiós al municipio, o la fecundidad de una red de gobierno local”. Proposiciones 28. Santiago de Chile: Ediciones SUR. 
Universidad de Rancagua.

(2002). El fantasma federal en Chile. Santiago de Chile: FES-

(2007). "Presicracia centralista en Chile: impuesta por la dictadura derechista y administrada por la centroizquierda paternalista". En: Carrión, Fernando. Descentralización en Ecuador: opciones comparadas. Quito: Flacso.

$-$ (2008). Infante y el Valdiviano Federal, La Voz Terrible. Santiago de Chile: Universidad Bolivariana. $-$ (2011). "El MAPU y el rol transformador de las élites iluministas". En Revista de Ciencia Política, Vol. 31 (2), 2011, 187-206.

-(2013) La Conversión de los socialistas chilenos. Santiago: El Desconcierto.

--(2014). Descentralización Ya. Santiago: Ril. (2015). Territorios Rebeldes. Santiago: UAH.

- Van Gunsteren, Herman (1976). The Quest of Control: A critique of the rationalcentralrule approach in public affairs. London: Wiley.

- Véliz, Claudio (1984). La tradición centralista de América Latina. Barcelona: Ariel.

- Vicuña Mackenna, Benjamín (1989) (reimpresión). Los girondinos chilenos. Santiago de Chile: Editorial Universitaria.

- Villalobos, Sergio (1989). Portales: una falsificación histórica. Santiago de Chile: Editorial Andrés Bello.

- Vitale, Luis (1971). Las guerras civiles de 1851 y 1859 en Chile. Serie Historia Social.Concepción: Universidad de Concepción.

- Vovelle, Michel (1999). Les jacobins. De Robespierre à Chevènement. París: Éditions la Découverte.

- Tagle, Matías (1991). “Conflictos, regímenes y crisis políticas”. En: Raúl Atria y Tagle, Matías: Estado y política en Chile. Santiago de Chile: CPU.

- Wright Mills, Charles (1957). La élite del poder. México: FCE.

- Zeitlin, Maurice (1984). The Civil Wars in Chile. Princeton, NJ: Princeton University Press. 